\title{
Sensitivity analysis of a computer code for modelling confined fires
}

\author{
P. Ciambelli, M. G. Meo, P. Russo \& S. Vaccaro \\ Department of Chemical and Food Engineering, University of Salerno, Italy
}

\begin{abstract}
Full scale experiments of tunnel fires are expensive and difficult to be carried out while tunnel fires simulation by computer modelling is cheaper and faster. Therefore, such a tool can replace the experiments if simulation results are recognized to be reliable and reflecting the reality. A computational fluid dynamics (CFD) code AIR was employed for the description of the transient behaviour of confined fires. The code solves the balance equations for the conservation of mass, momentum, energy and gas species within the physical domain of interest and yields local predictions of temperature, velocity, smoke, species concentration, etc, as a function of time. Firstly a sensitivity analysis of the computer code with respect to its parameters was performed, then experimental data from literature were employed to test the computer code performances. Simulations were obtained for a small scale steady-state tunnel fire and for an unsteady-state tunnel fire. AIR's performances in simulating tunnel fires were fair. Results depend on code parameters (grid fineness, number of iterations and step time interval) and on initial and boundary conditions such as temperatures, ventilation, heat release rate and radiant and convective heat transfer at the walls. The main AIR's limit is that it cannot manage radiative heat exchange with the walls and time variable boundary conditions as those encountered in transient tunnel fires.
\end{abstract}

Keywords: tunnel fires, CFD modelling, sensitivity analysis, temperature profiles, $\mathrm{CO}$ and smoke concentration profiles.

\section{Introduction}

Fires developing in enclosures constitute a terrible threat for lives. The danger of enclosure fires, besides to the temperature increase, derives mainly from the 
presence of high concentrations of smoke, which can significantly reduce the visibility and then the possibility for people to reach escape routes, and of $\mathrm{CO}$, which attenuate reaction faculties up to a total unconsciousness. Indeed, most of the deceases caused by fires are due to inhalation of carbon monoxide and consequent poisoning [1, 2]. Among the various enclosure fires those in road and railway tunnels are particularly dangerous because the amount of firing material can be huge and the length of the way to escape outside the enclosure can be in some cases several kilometres. As a result, road and railway tunnel fires where many people lost their lives represent tragic real examples [3]. To prevent the occurrence or at least to mitigate the consequences of such events, existing tunnels should be upgraded and new tunnels should be equipped with efficient fire protection systems. To this aim, faithful predictions of the fire-induced air velocity, temperature, $\mathrm{CO}$ and smoke concentration in enclosure fires and of their evolution with fire protection systems such as ventilation are fundamental. Fire modelling has been made by zone models [2, 4-6] and by field or computational fluid dynamics (CFD) models [7-9]. CFD models are computationally more intensive than zone models, which uses assumed smoke layer functions. However, the former yield more accurate solutions for the actual space and a better mean of comparing system changes. Therefore, CFD allows the evaluation of the effectiveness of fire fighting strategies, the assessment of relative benefits and the comparison of the effects of differing approaches [10]. However, enclosure fire modelling is difficult. Indeed, an enclosure fire is a complex phenomenon involving mass transfer, combustion, turbulence and radiative, convective and, possibly, conductive heat transfer. Such phenomena interact with each other during fire. Therefore, besides to mass and momentum balance equations further submodels for buoyancy, compressibility, turbulence, and thermal radiation are, generally, employed [11].

Obviously, to be really reliable for safety studies CFD models must be able to reproduce closely not only the overall known behaviour of fires in tunnel, but also measured values from controlled tunnel fire experiments. Therefore, CFD models and the associated physical sub-models need to have been validated by means of sensitivity analysis against simple cases and to be suitable for the particular application. Such a validation plays an important role in generating confidence in the application of a CFD fire model to tunnel problems, and in understanding the critical parameters and limitation of this model [12].

The aim of the present study is to examine the performance of a relatively simple field model (AIR) developed by D'Anna and Kent [10] and Novozhilov et al. [13-14] in the description of tunnel fires. A sensitivity analysis of the computer code with respect to its parameters was performed and experimental data from literature were employed to test the code. In particular, simulations results were obtained for a small scale steady-state tunnel fire [11], and for an unsteady tunnel fire [15-18]. Such results are compared and evaluated versus the pertaining experimental data. 


\section{CFD}

The computational fluid dynamics model employed in this work [10, 19] uses given boundaries, heat sources and air inlets to predict three-dimensional distributions of conditions within the space. The code checks mass and energy balances and checks for inconsistencies in input specifications. Solutions can be steady state or time dependent. The governing equations are solved using the finite volume method in a Cartesian computational grid with variable cell size. Embedded fine grids to any level may be placed within coarse grids to improve resolution and efficiency. The "HYBRID first order upwind" scheme is generally used to represent the convection-diffusion terms in the conservation equations, although high-order discretization schemes are also available in the code. The SIMPLER algorithm is used to calculate the pressure field. The algebraic equations are solved using the line-by-line TriDiagonal-Matrix Algorithm (TDMA). AIR employs the buoyancy-augmented $k-\varepsilon$ model to represent turbulent transport, and the Eddy Break-Up combustion model. Wall boundary conditions are treated using the wall function approach to eliminate the need to resolve the laminar sub-layer. The standard expressions for momentum and convective heat/scalar fluxes are modified to include the effect of wall roughness.

The model does not account for radiation, as well as for walls heating. As suggested in the literature [20-22], a solution to the first lack can be found by empirically setting in the code an Heat Release Rate (HRR) lower than the actual, which would represent the real energy available for gas heating by convection (in this way HRR becomes a sort of convective heat release rate). In other terms, a fraction of the total heat generated by the fire is assumed to be transmitted to the tunnel walls via radiation by flame, smoke and hot gases. This radiative fraction depends, besides to fire size and tunnel geometry, on fuel type and ventilation, and in the literature it is reported to vary between 0.2 and 0.4 [20-22].

\section{Experimental data from the literature}

A typical feature of CFD models is the ability to simulate both full and reduced scale events, either steady or unsteady. As mentioned in the Introduction, simulations results were obtained for two different tunnel fires of which experimental data were available in the literature, i.e. a small scale steady-state tunnel fire [11], and a full scale unsteady fire in the Runehamar tunnel (UPTUN project) [16-19].

\subsection{Small scale fire}

The small scale tunnel was made of insulating materials (perspex, silica glass) and of thermo-resistant material (alumina) near the fire. It was $6 \mathrm{~m}$ long, with rectangular cross section $(0.3 \mathrm{~m}$ high and $0.9 \mathrm{~m}$ wide). The fire source was located $1.5 \mathrm{~m}$ from the inlet section $(\mathrm{x}=0)$ in the middle of the floor. The burner dimensions were $0.18 \times 0.15 \mathrm{~m}^{2}$ with the longer side along the tunnel axis. Liquefied petroleum gas (LPG) was used as fuel and longitudinal ventilation was simulated by an axial fan. In the experimental study, two steady-state heat release rates, 3.15 and 
$4.75 \mathrm{~kW}$, were employed under four different ventilation flow velocities, i.e. 0.13 , $0.31,0.52$ and $0.61 \mathrm{~m} / \mathrm{s}$. Available data refer only to few conditions, and are expressed as temperature profiles along verticals on the tunnel centreline at three cross-sections, one located upstream the fire (at $\mathrm{x}=0.9 \mathrm{~m}$ ) and two located downstream the fire (at $\mathrm{x}=3.3 \mathrm{~m}$ and $\mathrm{x}=5.1 \mathrm{~m}$ ). Simulations were carried out with HRR of $3.15 \mathrm{~kW}$, and ventilation velocity of $0.13 \mathrm{~m} / \mathrm{s}$.

\subsection{Full scale fire}

The experimental results of the full scale fire are relevant to tests carried out in September 2003 by SP Swedish National Testing and Research Institute in the context of UPTUN [12]. The tests were performed in Norway in an abandoned two way asphalted road tunnel $1650 \mathrm{~m}$ long, $6 \mathrm{~m}$ high and $9 \mathrm{~m}$ wide, with a slope varying between $1 \%$ and $3 \%$. Tests were performed with a fire of a HGV cargo set-up, located at the centre of the left hand lane, loaded with mixtures of different cellulose and plastic materials or with furniture and fixtures. The commodities were placed on boards on a rack storage system to simulate a HGV measuring $10450 \mathrm{~mm}$ by $2900 \mathrm{~mm}$. The total height was $4500 \mathrm{~mm}$. The height of the platform floor was $1100 \mathrm{~mm}$. The CFD simulations were focused on a test carried out with wood pallets and PE plastic pallets (total weight $10911 \mathrm{~kg}$ ) in the ratio $82 / 18 \mathrm{wt} \%$, yielding a HRR peak of about $200 \mathrm{MW}$ after $20 \mathrm{~min}$. In order to create a longitudinal flow inside the tunnel, two mobile fans, able to create a longitudinal flow of $3 \mathrm{~m} / \mathrm{s}$ to minimize the risk for backlayering, were used. The centre of the fire was located $563 \mathrm{~m}$ from the tunnel entrance. Ignition took place at the upstream side of the HGV-trailer. For safety reasons in the fire zone the tunnel was protected with a passive fire protection system made of fire-resistant and insulating PROTOMATECT $®-T$ boards to prevent the tunnel ceiling rocks from falling down. A tunnel length of $75 \mathrm{~m}$ was protected with boards.

\section{Simulations}

\subsection{Small scale fire}

The AIR simulations [23] of the small scale steady-state tunnel fire were made by setting the calculation domain just the same of the experimental volume $(6 \mathrm{~m}$ long, $0.9 \mathrm{~m}$ wide and $0.3 \mathrm{~m}$ high), and dividing it in 180,000 cells $(150 \times 30 \times 40)$. The grid was made finer along the vertical axis to better simulate smoke buoyancy. To reproduce the experimental ventilation, a uniform $0.13 \mathrm{~m} / \mathrm{s}$ airflow was supplied at the $\mathrm{x}=0$ section. The convective coefficient $U$ was set to zero (adiabatic walls) along the whole tunnel. This is an acceptable approximation thanks to the wall materials, to the fact that the system is under steady-state conditions and to the likely high wall temperatures, especially around the fire.

As mentioned, AIR does not account for radiation, and then, simulations were performed in this case employing values of the radiant fraction of the actual HRR of 0.1 and 0.2 . 


\subsection{Full scale fire}

The Runehamar tunnel was exemplified as a rectangular tube, $9 \mathrm{~m}$ wide and $6 \mathrm{~m}$ high, but in the tunnel zone with the walls coated by protecting boards for which a reduced section $7,2 \times 5 \mathrm{~m}^{2}$ was employed. The calculation domain was set $700 \mathrm{~m}$ long, from $140 \mathrm{~m}$ upwind the fire centre up to the downstream tunnel portal. Tunnel slope was simulated and a uniform $3 \mathrm{~m} / \mathrm{s}$ airflow was imposed at the $\mathrm{x}=0$ section to reproduce the experimental longitudinal ventilation [23].

At first, sensitivity analysis of the effects of some code parameters was carried out by launching several runs with different values of such parameters. Specifically, the influence of grid fineness, integration time step and maximum number of iterations per time step on the stability of the solution and on the accuracy and the behaviour of the results was studied. For each run the simulation results were compared with experimental data and the required computing time was recorded. These simulations for sensitivity analyses were carried out with a strong approximation, to quickly and simply set boundary conditions values: the heat transfer convective coefficient $U$ was set to zero (adiabatic walls) along all the tunnel length. Finally, the optimization of the code parameters led to these values:

- The simulated tunnel was divided into 175,9 and 15 cells along the three directions (base grid), and embedded finer grids were used in the fire area, with a total of about 170,000 cells;

- The maximum number of iterations per time step was set to 100 ;

- The transient simulations were taken up to $50 \mathrm{~min}$ with time step of $0.5 \mathrm{~min}$.

With this set of parameters, approximately $9 \mathrm{~h}$ of computing time was required for the simulation, and the results were stable and followed the experimental behaviour.

\section{Results and discussion}

\subsection{Small scale fire}

The quality of the simulation can be appreciated comparing (fig. 1) the available experimental data of temperature profiles, measured along verticals at the centreline of the tunnel upstream $(x=0.9 \mathrm{~m})$ and downstream $(\mathrm{x}=3.3 \mathrm{~m})$ the fire, and simulations results.

From fig. 1(a) it is evident that the supplied airflow $(0.13 \mathrm{~m} / \mathrm{s})$ is not able to prevent hot gases backlayering since upstream gases warm up, as shown by both measured and calculated temperatures. In addition, figs 1(a) and 1(b) show that the calculated upper layer hot gases temperatures are always overestimated and that such temperatures oscillate with the number of iterations with amplitude of about $50^{\circ} \mathrm{C}$. As a result the solution does not converge even after several thousands iterations. This is probably due to the flow pattern set, intrinsically instable (as proved by backlayering), which does not allow AIR code to get convergence and stability with such boundary conditions. For these tests experimental measurements of pollutants and oxygen concentrations were not 
available so, unfortunately, it is not possible to assess the consistence of simulated values of such variables.
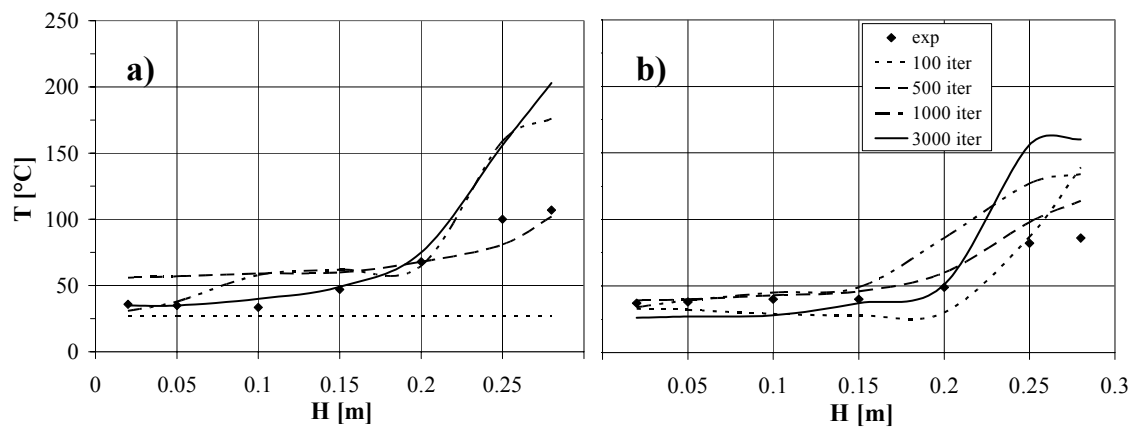

Figure 1: Experimental and calculated (90\% HRR) temperature profiles along the tunnel height at the centreline. Distances from the tunnel entrance: (a) $\mathrm{x}=0.9 \mathrm{~m}$, (b) $\mathrm{x}=3.3 \mathrm{~m}$.

\subsection{Full scale fire}

The comparison between experimental and calculated $\mathrm{CO}$ and $\mathrm{O}_{2}$ concentrations profiles, shown in fig. 2 in the case of $\mathrm{O}_{2}$, is good at relatively short distances from the floor (fig. 2(b)) whole it becomes poor as the distances approach the tunnel height. Moreover calculated $\mathrm{CO}$ and $\mathrm{O}_{2}$ concentrations vary little with the actual HRR set, as shown for $\mathrm{O}_{2}$ in fig. 2 .
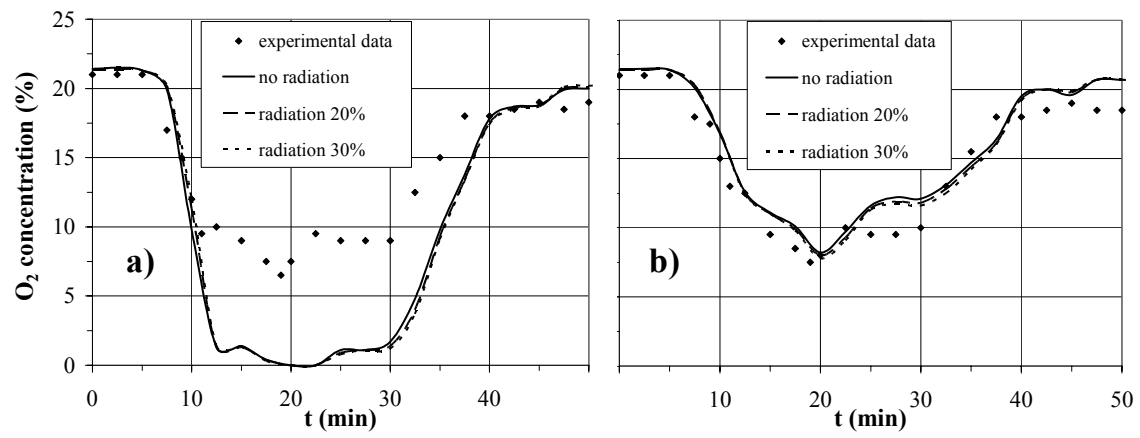

Figure 2: $\quad$ Experimental and calculated $\mathrm{O}_{2}$ concentrations, $458 \mathrm{~m}$ downstream the fire at the tunnel centreline, at different heights: (a) $\mathrm{z}=5.1 \mathrm{~m}$, (b) $\mathrm{z}=1.8 \mathrm{~m}$.

This result derives, on the one hand, from the fact that the computer code employs both HRR and the net calorific value of the fuel to estimate the evolution with time of smoke, $\mathrm{CO}$ and $\mathrm{O}_{2}$ concentrations and, on the other hand, from the fact that during the experimental tests HRRs were measured using oxygen consumption calorimetry. Therefore, in the simulations where the 
assumed HRR was a portion (i.e. $80 \%$ or $70 \%$ ) of the experimental value, the net calorific value of the fuel was decreased proportionally to maintain the same ratio between HRR and the net calorific value, in order to keep the fuel combustion rate constant and consequently to allow the correct computation of pollutant concentrations independently of the assumed HRR value.

In contrast with what observed for $\mathrm{O}_{2}$, the time profiles of temperature along the tunnel depend strongly on the HRR value (fig. 3). Results in fig. 3 also show that the mere change of HRR does not allow the correct reproduction of the experimental data, neither in the tunnel zone protected by insulating and refractory panels (temperatures are underestimated: figs. 3(a) and 3(b)), nor downstream in the zone with rock walls, where temperatures are instead greatly overestimated (figs. 3(c) and 3(d)).
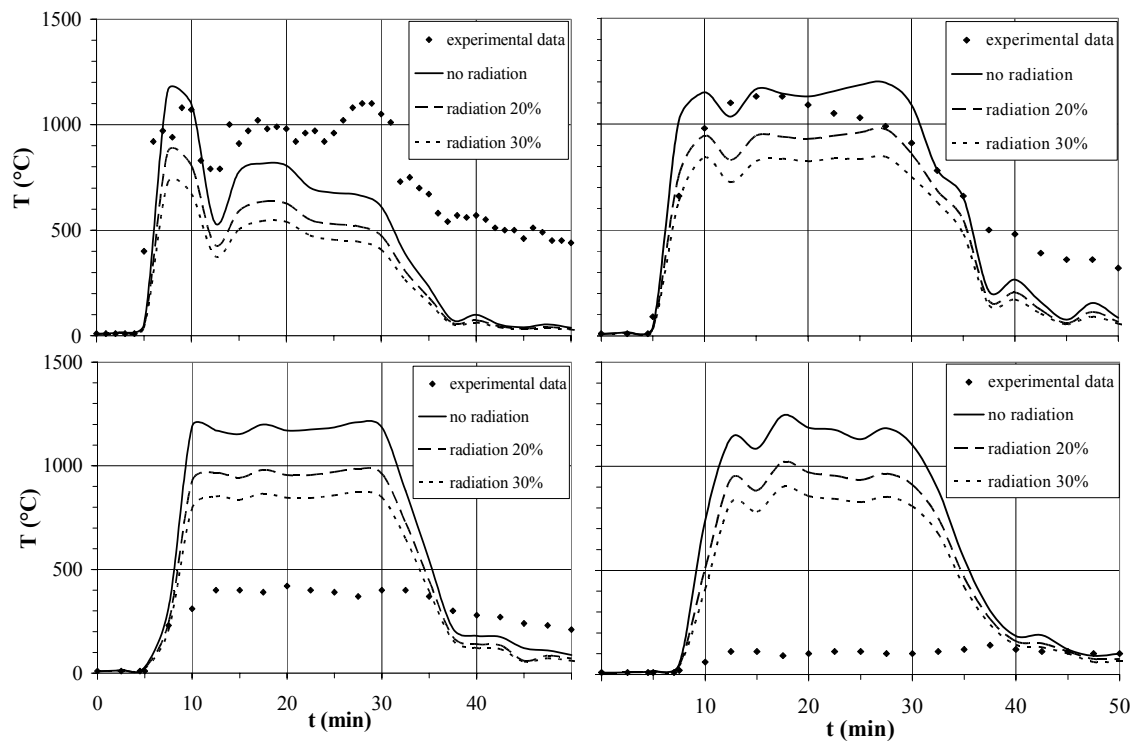

Figure 3: Experimental and calculated temperature profiles at the tunnel centreline, $0.3 \mathrm{~m}$ under the ceiling: (a) fire centre, (b) $40 \mathrm{~m}$ downstream the fire, (c) $150 \mathrm{~m}$ downstream the fire, (d) $458 \mathrm{~m}$ downstream the fire.

In particular, figs. 3(a) and 3(b) suggest that insulating panels really make adiabatic the region where fire develops, being the reduced HRR insufficient to heat the gases at the measured value. Instead, well downstream such a region the same HRR appear too high leading to a huge overestimation of the gas temperature (figs. 3(c) and 3(d)) and suggesting that relevant convective heat exchange between gases and tunnel walls occurs. Differences take place also when the fire is practically extinguished $(\approx 40 \mathrm{~min})$. In this case, indeed, whatever the distance from the fire but close to the tunnel exit portal (fig. 3(d)), the gas temperatures are underestimated (fig. 3). This likely means that when the fire is off, tunnel walls, heated up by the gas when the fire was developing, give 
back part of the heat making gas temperature higher than that expected. However, with respect to the observed discrepancies between experimental and computed results, it is worth noting that the modelling of the chosen tunnel fire is particularly difficult because of the presence of the insulating and refractory panels mounted on the walls in the region where fire develops and for further $50 \mathrm{~m}$ downstream. Indeed, their presence changes the geometry and the transport characteristics of the system influencing both fluid dynamics and heat transfer properties.

On the basis of the above analysis, some changes have been made to the parameters and boundary conditions. Specifically, such changes were addressed to take into account heat losses to the walls via radiation and convection as long as the fire was fully developed and the reverse heat transfer from hot walls to gases after the fire extinguishment. However, as AIR cannot model wall heating with time during fire, actual convective heat transfer at walls may be reproduced only if wall temperature $\left(T_{\text {wall }}\right)$ is changed cell by cell in space and step by step in time. Obviously, this complicated and tiresome method cannot be both accurate and useful in simulations.

Recognised that radiation and convection in tunnel fires are very important, a more detailed simulation of the heat transfer phenomena was implemented. The actual HRR was used and the tunnel length was divided into three zones: the first comprising the board coated region, and the other two each covering part of the remaining tunnel length. All the heat losses to the walls were modelled using lumped heat transfer coefficients and wall temperatures that accounted for both radiation and convection, and were determined as time and space averages. In addition, the total fire duration was split into shorter time intervals. Finally, using these settings, two longitudinal ventilation velocities $(3 \mathrm{~m} / \mathrm{s}$ and $2.5 \mathrm{~m} / \mathrm{s})$ were tried, in order to best reproduce the experimental airflow generated by fans.

The results of such simulations show a good agreement with experimental measurements either for gaseous species concentrations (fig. 4) or for gas temperatures (fig. 5). $\mathrm{CO}$ and $\mathrm{O}_{2}$ concentrations downstream the fire depend on the supplied airflow: the greater the ventilation velocity, the lower the oxygen concentrations and the higher the carbon monoxide concentrations (fig. 4).
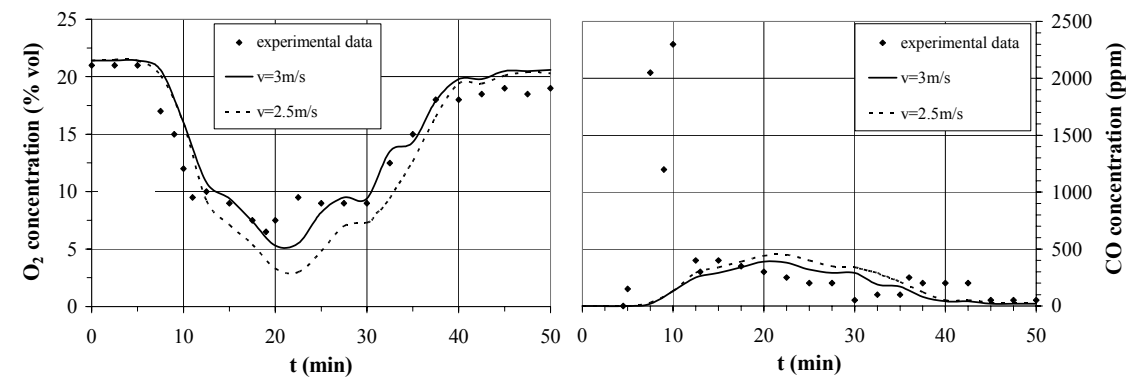

Figure 4: Experimental and calculated time profiles of $\mathrm{O}_{2}$ (a) and $\mathrm{CO}$ (b) concentrations. $100 \%$ HRR, variable $U$ and $T_{\text {wall, }} 458 \mathrm{~m}$ downstream the fire at the tunnel centreline; distance from the floor: $\mathrm{z}=5.1 \mathrm{~m}$. 
Moreover, the run carried out with $3 \mathrm{~m} / \mathrm{s}$ air velocity gives results that seem to come closer to experimental profiles. Instead, $2.5 \mathrm{~m} / \mathrm{s}$ air velocity seems more appropriate for the description of temperature profiles both in the tunnel zone protected by boards and in the zone with rock walls, as shown in fig. 5 .
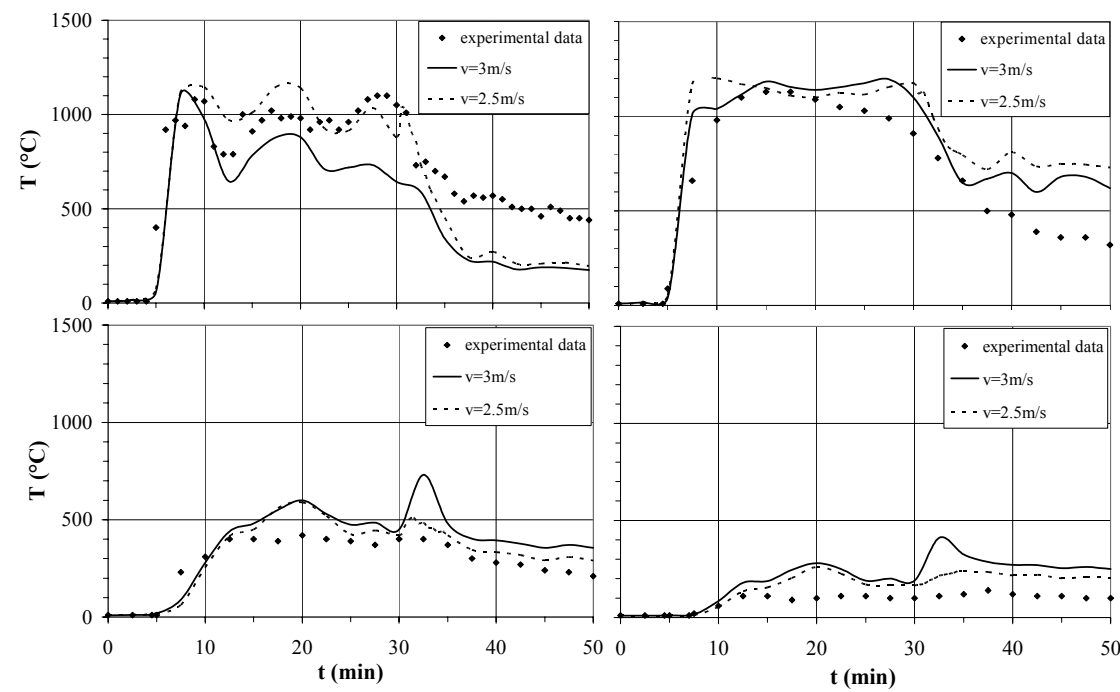

Figure 5: Experimental and calculated time profiles of temperature at the tunnel centreline, $0.3 \mathrm{~m}$ below the tunnel ceiling. $100 \% \mathrm{HRR}$, variable $U$ and $T_{\text {wall: }}$ (a) fire centre, (b) $40 \mathrm{~m}$ downstream the fire, (c) $150 \mathrm{~m}$ downstream the fire, d) $458 \mathrm{~m}$ downstream the fire.

\section{Conclusions}

On the whole, simulations results of pollutants and $\mathrm{O}_{2}$ concentrations and of gas temperatures describe fairly well the experimental values. However, such results were obtained after some modifications of boundary conditions, not possible in the normal AIR settings. Therefore, improvements of the code, especially concerning the boundary conditions management, are needed to accurately predict the behaviour of tunnel fires and to allow the use of the model for reliable fire safety engineering design.

\section{Acknowledgement}

The authors wish to thank Professor J. Kent for his helpfulness and for making available $A I R$ code. 


\section{References}

[1] Pitts, W.M., The global equivalence ratio concept and the formation mechanisms of carbon monoxide in enclosure fires, Progress in Energy and Combustion Science, 21(3), pp. 197-237, 1995.

[2] Duong, D.Q., The accuracy of computer fire models: some comparisons with experimental data from Australia. Fire Safety Journal, 16, pp.415-431, 1990.

[3] Vuilleumier, F., Weatherill, A. \& Crausaz, B., Safety aspect of railway and road tunnel: example of the Lötschberg railway tunnel and Mont-Blanc road tunnel, Tunnelling and Underground Space Technology, 17(2), pp. 153-158, 2002.

[4] Jones, W.W., A review of compartment fire models, NBSIR 83-2684, pp. 1-38, 1983.

[5] Dembsey, N.A., Pagni, P.J. \& Williamson, R.B., Compartment fire experiments: comparison with models, Fire Safety Journal, 25(3), pp. 187-227, 1995.

[6] Peacock, R.D., Reneke, P.A., Forney, C.L. \& Kostreva, M.M., Issues in evaluation of complex fire models, Fire Safety Journal, 30(2), pp. 103-36, 1998.

[7] Yang, K.T., Recent development in field modelling of compartment fires, JSME International Journal Series B, 37(4), pp. 702-17, 1994.

[8] Beard, A.N., Fire models and design, Fire Safety Journal, 28(2), pp. 117-38, 1997.

[9] Cox, G. \& Kumar, S., Fielding modelling of fire in forced ventilated enclosures, Combustion Science Technology, 52(1), pp. 7-23, 1987.

[10] D'Anna, A. \& Kent, J., Modelling of enclosed fires and smoke dispersion by computational fluid dynamics, La rivista dei combustibili, 56(3), pp. 95-103, 2002.

[11] Xue, H., Ho, J.C. \& Cheng, Y.M., Comparison of different combustion models in enclosure fire simulation, Fire Safety Journal, 36(1), pp. 37-54, 2001.

[12] Miles, S.D., Kumar, S. \& Andrews, R.D., Validation of a CFD model for fires in the Memorial Tunnel, Proc. of the $1^{\text {st }}$ Int. Conf. on Tunnel Fires and One Day Seminar on Escape from Tunnels, Lyon, France, pp. 159-168, 5-7 May 1999.

[13] Novozhilov, V., Moghtaderi, B., Fletcher, D.P. \& Kent, J.H., Computational Fluid Dynamics Modelling of Wood Combustion, Fire Safety Journal, 27(1), pp.69-84, 1996.

[14] Novozhilov, V., Harvie, D.J.E., Green, A.R. \& Kent, J.H., A Computational Fluid Dynamic Model of Fire Burning Rate and Extinction by Water Sprinkler, Combustion Science Technology, 123(1-6), pp. 227-245, 1997.

[15] Ingason, H. \& Lönnermark, A., Large Scale Fire Tests in the Runehamar tunnel - Heat Release Rate (HRR), Proc. of the Int. Symp. on Catastrophic Tunnel Fires, Borås, Sweden, pp. 81-92, 20-21 November 2003.

[16] Lönnermark, A. \& Ingason, H., Large Scale Fire Tests in the Runehamar tunnel - Gas temperature and radiation, Proc. of the Int. Symp. on 
Catastrophic Tunnel Fires, Borås, Sweden, pp. 93-103, 20-21 November 2003.

[17] Lemaire, T., Runehamar tunnel fire tests: Radiation, fire spread and backlayering, Proc. of the Int. Symp. on Catastrophic Tunnel Fires, Borås, Sweden, pp. 105-116, 20-21 November 2003.

[18] Lönnermark, A. \& Ingason, H., Large Scale Fire Tests in the Runehamar tunnel, Proc. of the Int. Symp. on Catastrophic Tunnel Fires, Borås, Sweden, Interactive CD-ROM, 20-21 November 2003.

[19] Kent, J.H., AIR 3.4 Manual.

[20] Mégret, O., Vauquelin, O., A model to evaluate tunnel fire characteristics, Fire Safety Journal, 34(4), pp. 393-401, 2000.

[21] Woodburn, P.J. \& Britter, R.E., CFD Simulation of a Tunnel Fire - Part I, Fire Safety Journal, 26(1), pp. 35-62, 1996.

[22] Tewarson, A., Generation of heat and chemical compounds in fires (Section 3, Chapter 4), The SFPE Handbook of Fire Protection Engineering, $2^{\text {nd }}$ edition, SFPE and NFPA, 1995.

[23] Meo, M.G., Simulazione numerica di incendi in galleria, Thesis in Chemical Engineering, University of Salerno, 2004. 